\title{
Versatility of Limberg and Its Modified Flaps in Post Firearm Wounds - A Case Series
}

\author{
Shabeer Hussain Mir ${ }^{\oplus 1}$, Harold Maxim Lewis ${ }^{\oplus 2}$, Simon Richard ${ }^{\circledR 3}$, Harish Arunmozhidevan ${ }^{\circledR 4}$ \\ ${ }^{1}$ Consultant, Department of Surgery, Sub District Hospital, Uri, Jammu and Kashmir, India, ${ }^{2}$ Consultant, Department of Surgery, Mallick Denar Charitable Hospital, \\ Kasragod and Kumble Cooperative Hospital, Kumble, Kerela, India, ${ }^{3}$ Assistant Professor, Department of Anaesthesia, Saraswathi Institute of Medical Sciences, Hapur, \\ UP, India, ${ }^{4}$ Consultant, Department of Orthopaedic, Augustine Jubilee Hospital, Ernakulam, Kerala, India.
}

\section{Abstract}

Background: The aim is to present our experience of Limberg and it's modified flaps in post firearm injuries (FAI). Subjects and Methods: A series of patients with FAI underwent Limberg and its modified flaps under general anaesthesia over a period of one year from June 2018 to May 2019. Results: All patients were young male aged between twenty-one and twenty-five years and in all patients, Limberg and it's modified local flap proved to be better than skin grafts with early return of patient functionality and did not require frequent dressing change. Conclusion: Our series indicates that Limberg and its modified flaps can be safely used to reconstruct post firearm moderate to large wounds.

Keywords: Limberg flap, Firearm injury, Wound, Fasciocutaneous flap

Corresponding Author: Simon Richard, Assistant Professor, Department of Anaesthesia, Saraswathi Institute of Medical Sciences, Hapur, UP, India.

E-mail: simon_richard65@yahoo.co.uk

\section{Introduction}

Tissue loss as a result of post firearm injuries inflicted on body parts can result in body defects. Over the years several methods have been used to recontruct the wound defects. Small wound defects can be closed primarily. However, moderate to large wounds need major surgical procedures based on skin flaps, musculocutaneous flaps, myoplasty and so on and so forth.
A time-tested alternative is the use of Limberg and its modified flaps. ${ }^{[1]}$ The biggest advantage of these flaps is primary closure of the donor wound defect. This flap is named after Prof Alexander Alexanderovich Limberg (1894-1974) from Linigard. ${ }^{[2]}$ This versatile flap combines the principles of rotation and advancement.

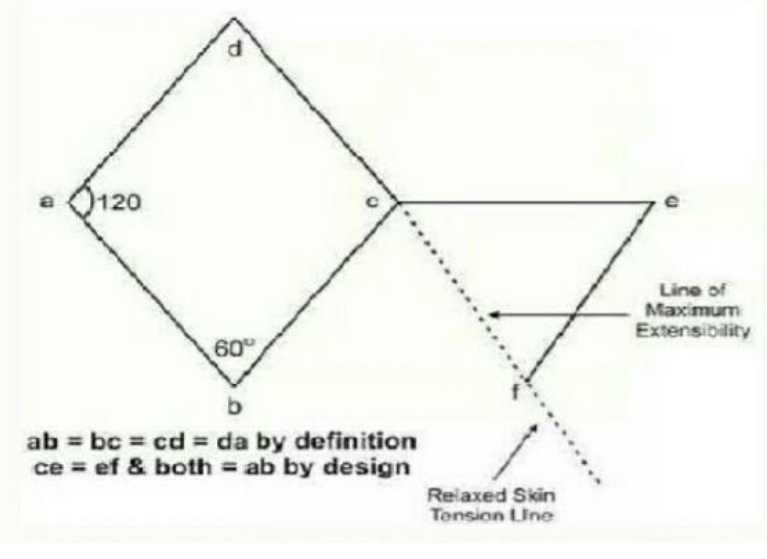

In 1962, Claude Dufourmental modified the Limberg local flap design. ${ }^{[3]}$ In this modification, the distal border of the local Limberg flap is placed on the line that bisects the angle between the short diagonal of Limberg defect and its adjacent side, the acute angle is still 60-75 degrees. Advantages of the modified Limberg local flap is that it widens the pedical of flap width and it increases the safety of flap grafting. ${ }^{[4]}$ 


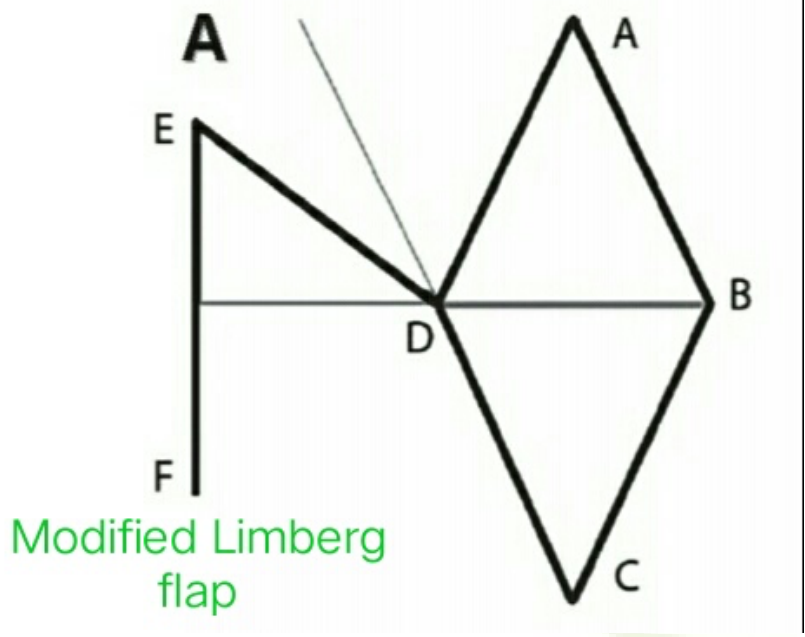

\section{Case 1}

A 22 years old male patient was admitted in our hospital with thoracic vertebra fracture at D5-6 level with moderate mid sacral region wound sustained post firearm injury. The wound dressing was done daily with $2 \%$ betadine and fusidic acid ointment for one week. Thereafter, the double Limberg local flap procedure was planned to cover the wound as the defect was moderate in size and the underlying sacral bone was exposed with little granulation tissue. The defect was measured preoperatively; it was 7 centimetres in both horizontal and longitudinal directions. After the preanaesthetic check up double Limbergs fasciocutaneous flap surgery was performed under general anaesthesia with standard monitoring.

Intraoperative care: After intubation the patient was put in jack knife position with strict monitoring of vital signs. Prior to surgical procedure marking of the operating site was done [Figure 1].

Then, debridement of the residual slough and excision of one centimetre of the extra- indurated margin was done. On the operating table measurement of the sacral wound was again performed, which measured $8 \mathrm{~cm}$ in both vertical and horizontal directions. Before any skin incision was made, further check of the skin availability and laxity was made with the thumb and fore fingers.

Flap design: For this purpose the wound defect was bisected at the centre into two halves of four centimetres each by drawing an imaginary horizontal line from either margin of the wound defect passing through the centre. On the left side of the wound defect, the base of the triangle of the flap was raised from the left lateral lumber region and on the right side of the wound defect; the base of the flap was raised from the right gluteal

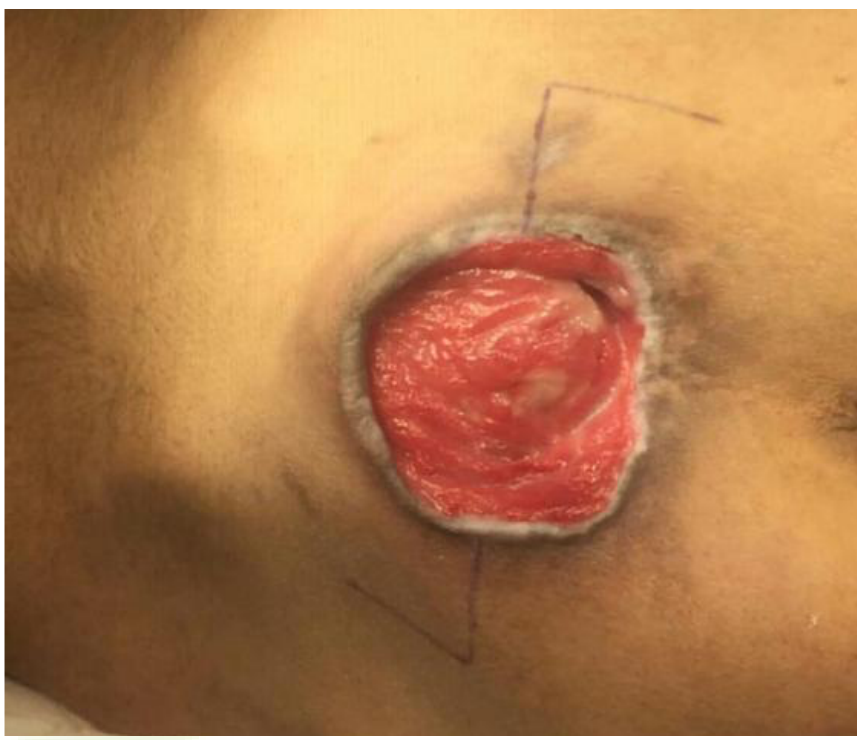

Figure 1: Marking of the operating site.

region. Thereafter, each of these two flaps were advanced and rotated in opposite directions and sutured in kissing fashion medially. Both the defects thus produced laterally were closed primarily.

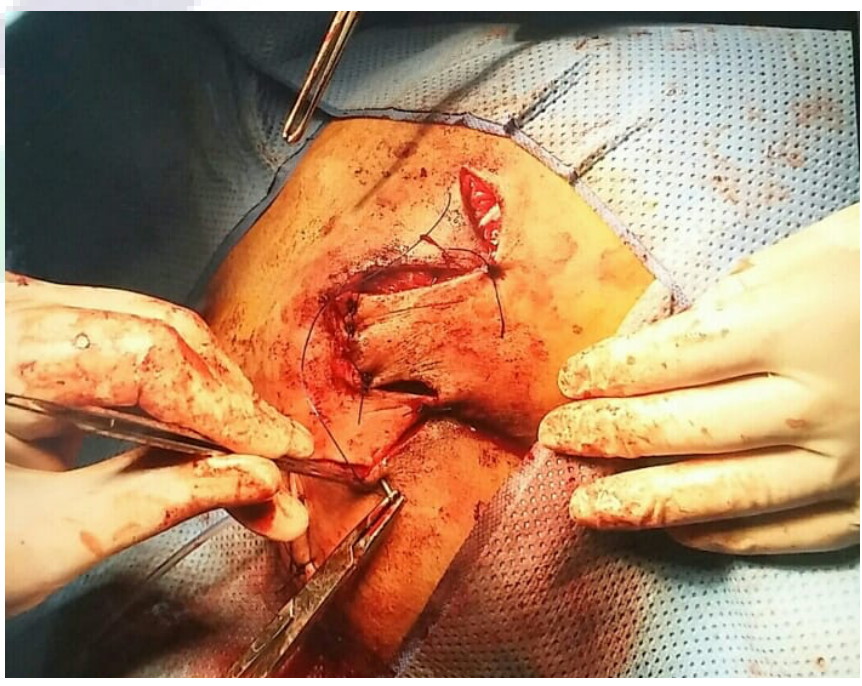

Figure 2: Intraoperative flap design.

Before the complete closure of the flaps, suction drain number 14 was inserted beneath each of the two donor flaps. Suture material used was $2 / 0$ polypropylene and the flaps were sutured in interrupted manner.

Postoperative period was uneventful. Patient was nursed in right or left lateral position. Suction drain and sutures 
were removed on the 5th and the 12th postoperative day, respectively.

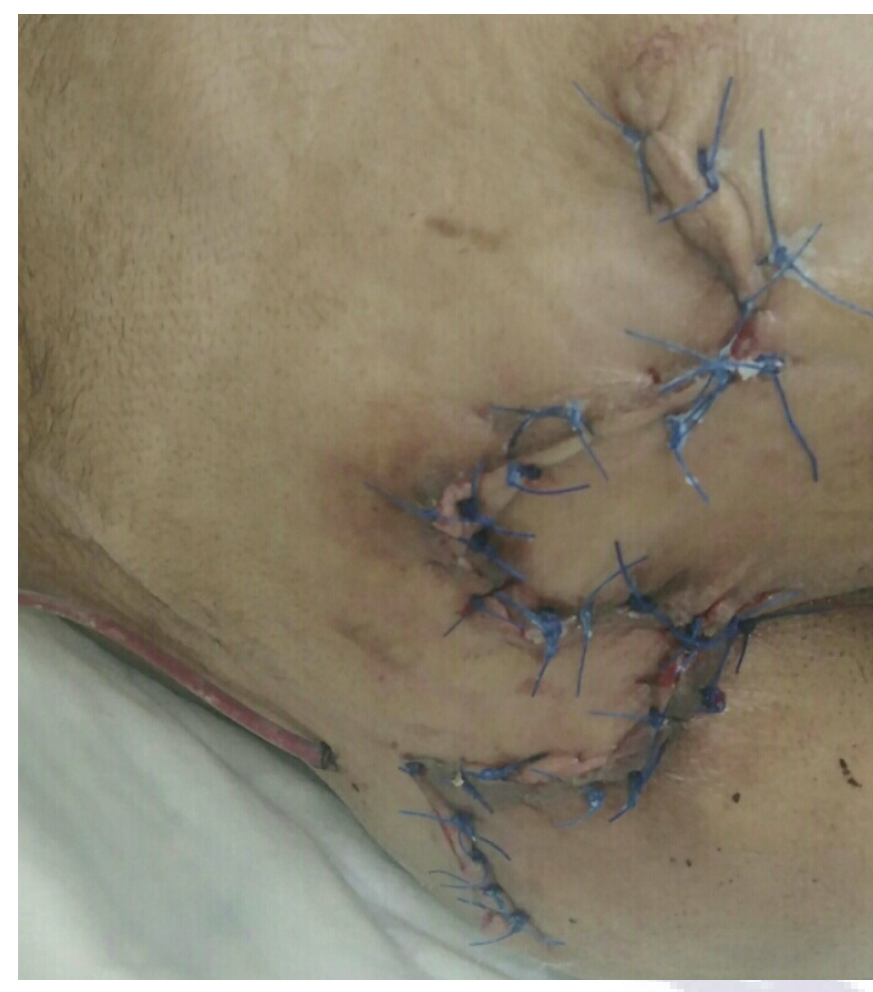

Figure 3: Flap at first post operative day.

We demonstrated successful double Limberg local flap to cover the post firearm sacral injury wound in this patient without any postoperative complication. The postoperative photograph taken after two weeks clearly shows that the deep sacral defect is filled with tissue of the same thickness and colour and with good vascularity of the fasciocutaneous flap.

\section{Case 2}

A 25 years old male with history of firearm injury (FAI) and exploratory laparotomy with primary resection anastomosis of sigmoid colon had moderate exit wound in the lumbar region. The exit wound dressing was done daily.

Subsequent to the lumbar wound debridement a moderately large wound defect developed for which modified Limberg local flap procedure was done under general anaesthesia. The procedure was done in jack knife position. Two suction drains of 12 number each were inserted. Both the wound defect and the donor site were closed primarily. Postoperative period was uneventful. The patient was discharged on the 10th postoperative day.

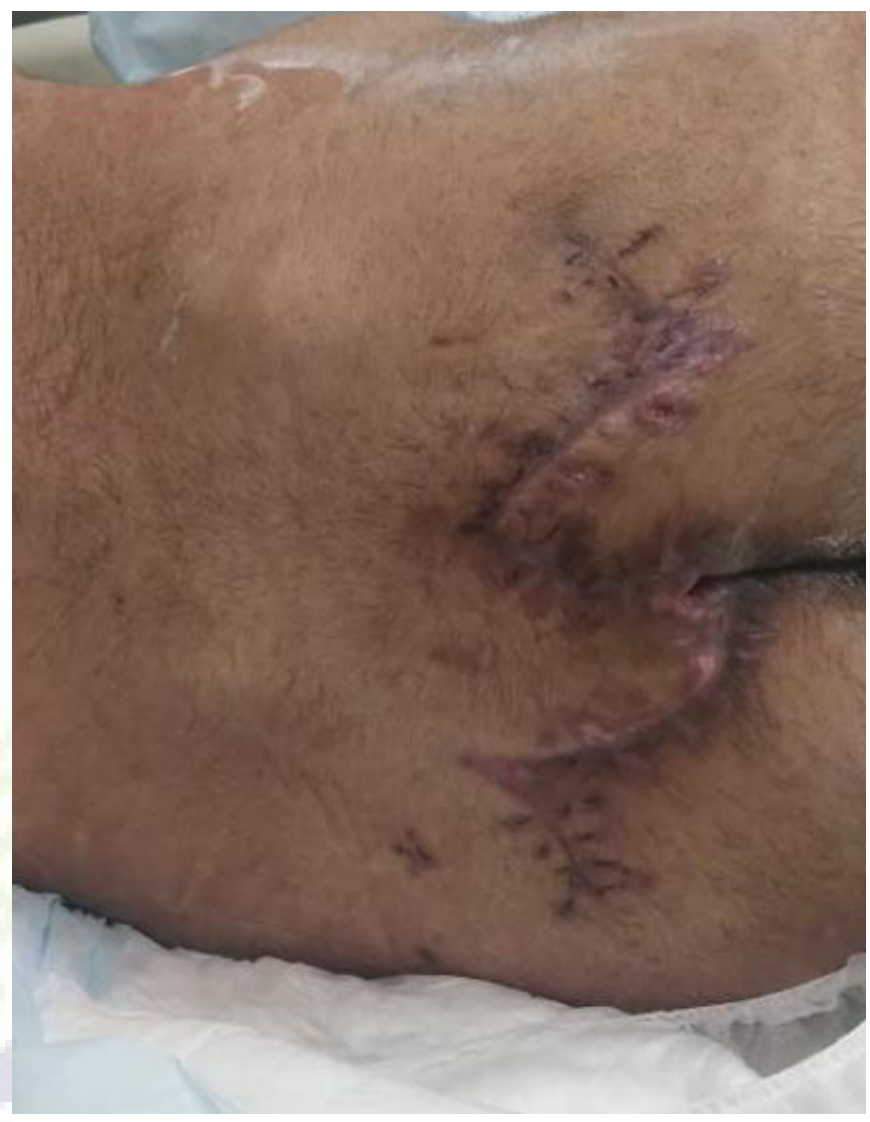

Figure 4: Wound flap after suture removal.

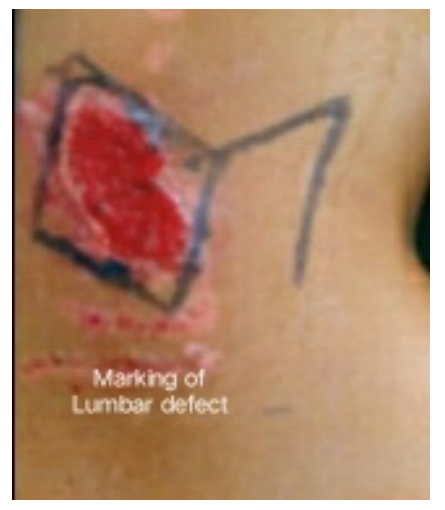

Figure 5: Marking of lumber wound defect. 


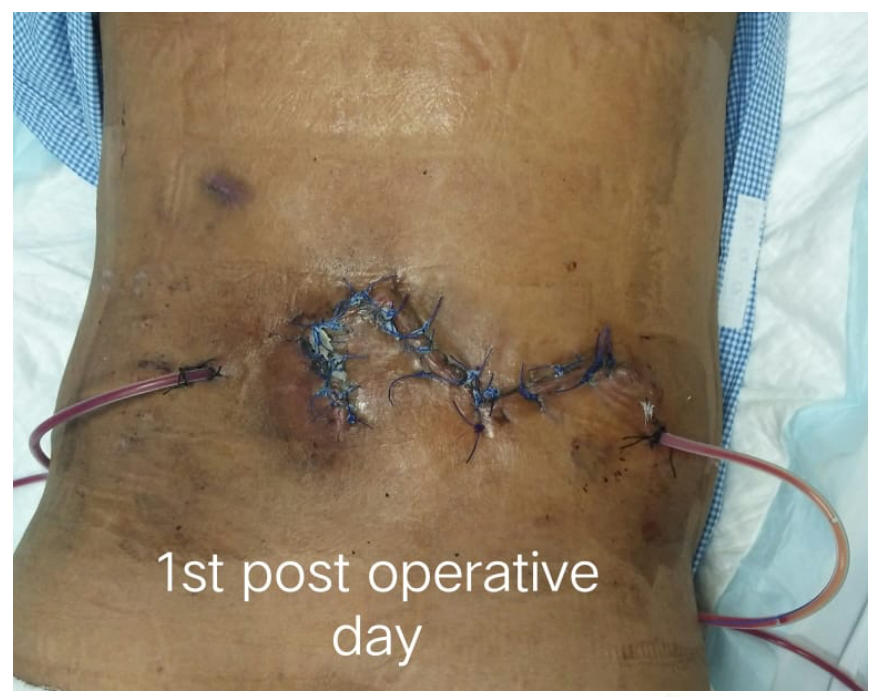

Figure 6: First postoperative day.

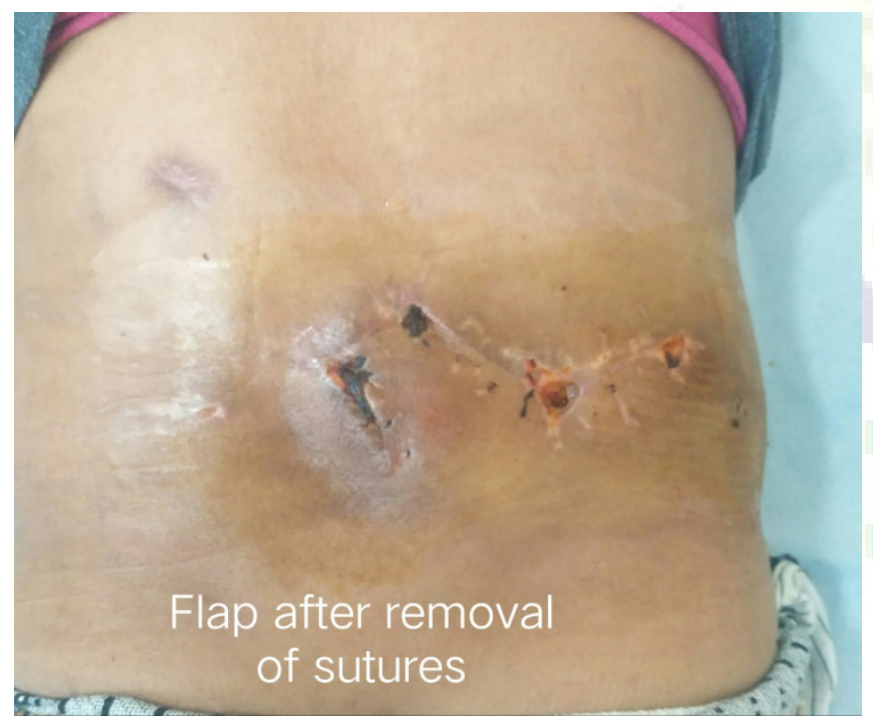

Figure 7: Limberg flap after removal of sutures.

\section{Case 3}

A 21 years old male was brought into Emergency Room (ER) with a history of isolated firearm injury (FAI) wound in the upper and medial aspect of the right buttock with exposed underlying sacral bone. Patient was initially managed with daily dressings for a week since the defect was contaminated. After the patient developed good granulation tissues, patient was prepared for modified Limberg flap to fill the wound defect. The procedure was carried under general anaesthesia in jack-knife position.

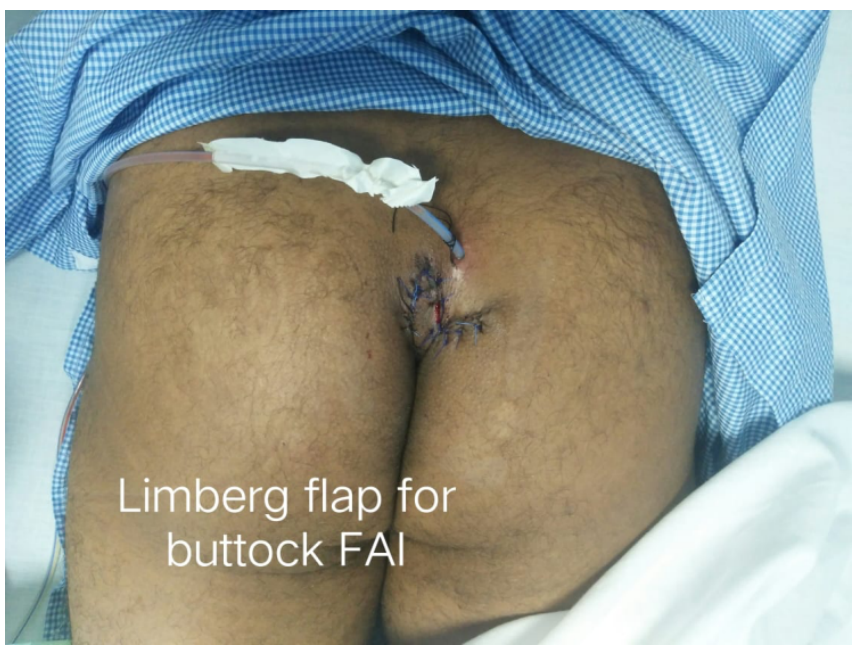

Figure 8: Limberg flap for FAI buttock wound.

The postoperative period was uneventful. The patient was discharged on the 10th postoperative day.

\section{Case 4}

A 25 years old male patient with a history of firearm injury and fracture right humerus had a large right sided axilloscapular wound defect. Initially, he was operated upon for open reduction and external fixation for humerus bone fracture. Serial debridement of axilloscapular wound was done under local anesthesia. Modified Limberg local flap was planned and successfully performed to fill the wound defect.

\section{Case 5}

A 22 years old male was brought to Emergency Room (ER) with a history of bomb blast injury resulting into left iliac fossa abdominal wound with exposed left iliac crest. Initially, serial debridement procedures were done under local anaesthesia. Patient's abdominal defect and exposed iliac bone were successfully covered with rhomboid local flap under general anaesthesia without any complication in the postoperative period. The patient was discharged on the 14 th postoperative day.

\section{Discussion}

Though, the rhomboid local flap can be used for closure of defect anywhere on the body, it is challenging to do in sacral region, ${ }^{[5]}$ hence, only dressing care is usually given for it to heal. We have demonstrated successful random rhomboid pattern skin flap grafting in five of our firearm-injured patients. 
The postoperative photographs clearly show that the deep defect is filled with tissue of the same thickness and colour and with good vascularity of the Limberg local skin flap, which has not occurred in another firearm injury case [Figure 9-11] the patient had refused the procedure, rather contracture with movement restriction resulted.

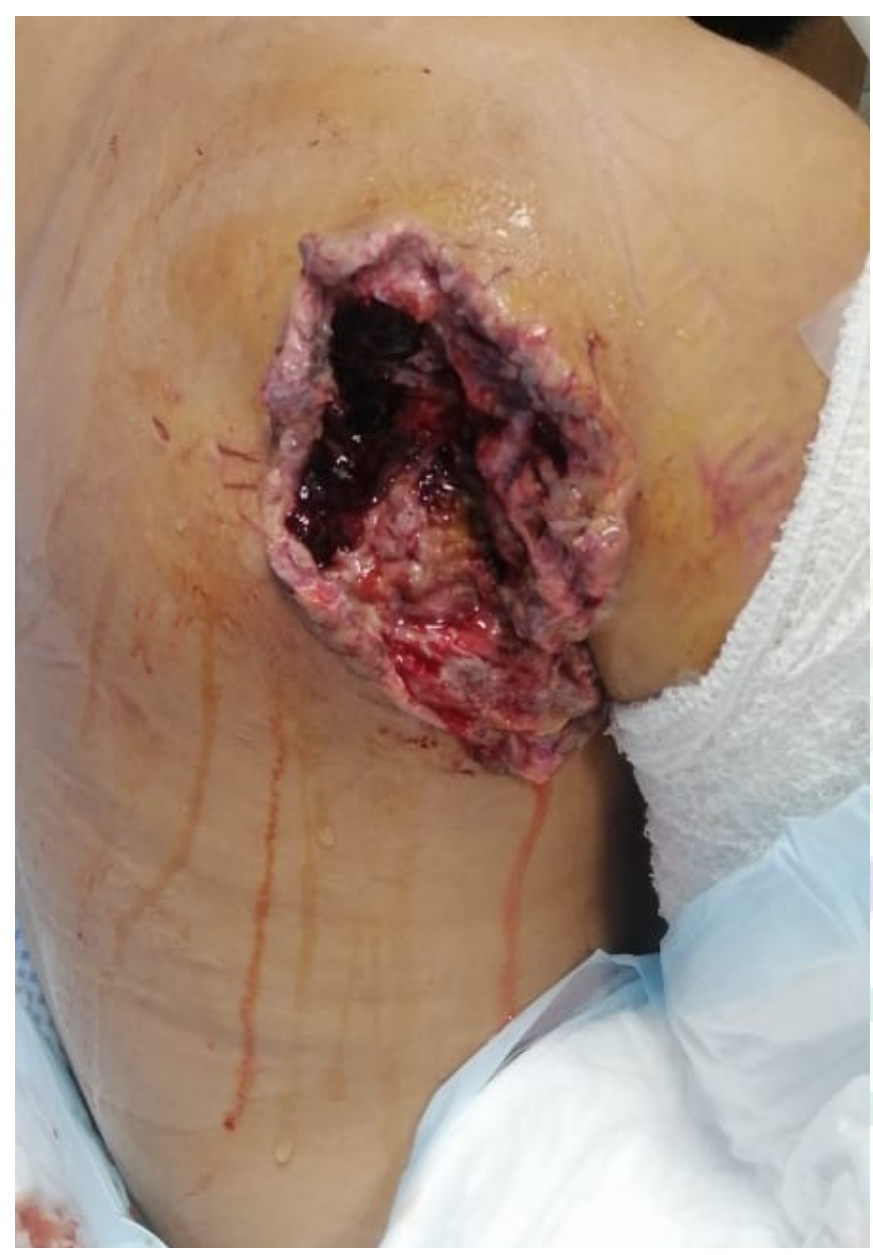

Figure 9: Right scapular post bomb blast wound defect.

Direct closure of a defect is easily done but when the size of a defect is larger, it becomes difficult to close primarily. Local flap is technically easy, aesthetically appealing requiring less operation time and follow up duration; and moreover, it bypasses grafts and tissue expansion procedures. Besides, early functionality, skin texture and colour of local flap match better. ${ }^{[6]}$

Plastic surgeons favour planned transposition flaps on the principle of rhomboid flap since they are simpler to do and can be used at any site of the body.

Dufourmentel, ${ }^{[7]}$ and Webster modified the rhomboid flap, which has become safer and increased angular ranges of the

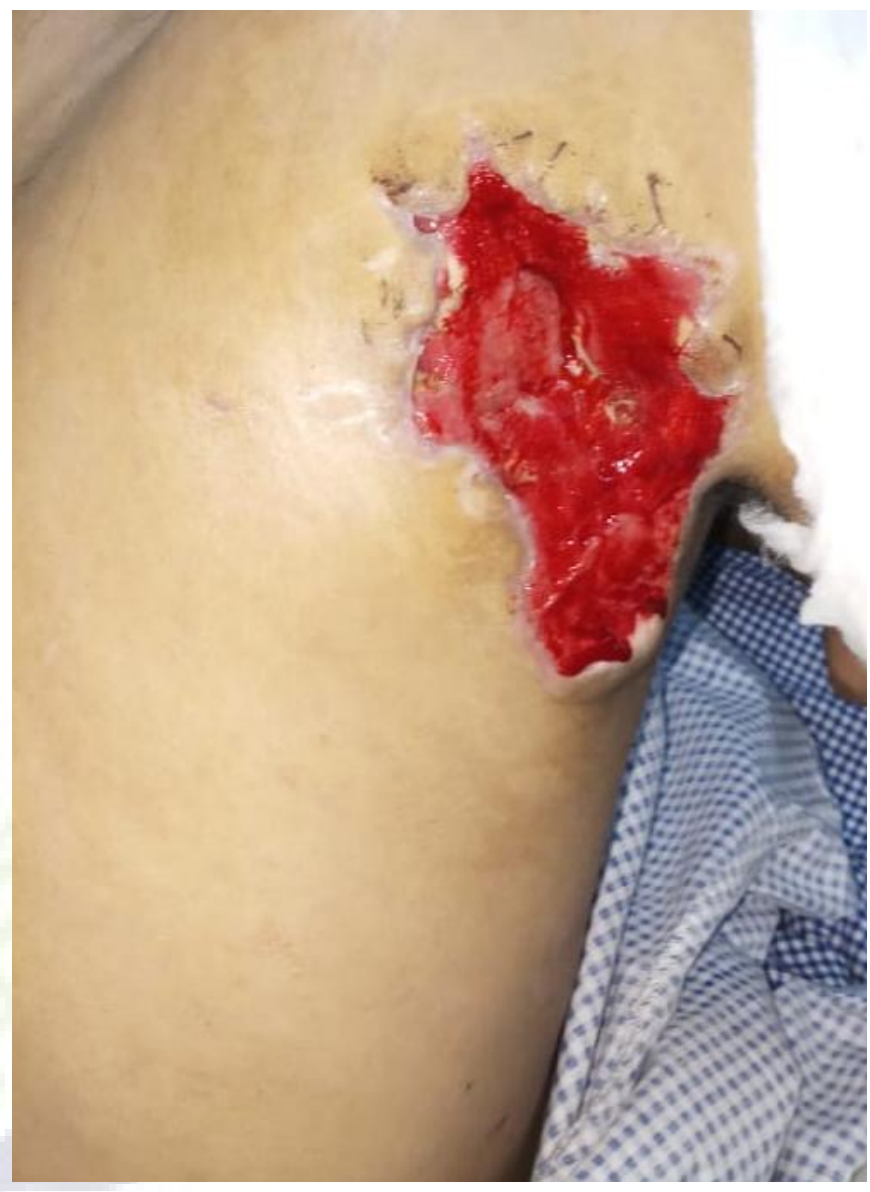

Figure 10: Well granulated wound.

flaps.

Like after ablative cancer surgeries, aesthetics are important in young patients with firearm injuries. A well-planned rhomboid flap is better than primary intention closure since the scars are parallel to the tension lines. ${ }^{[8-10]}$

Rhomboid local flap is better than skin grafts because return of patient functionality is early and does not require frequent dressing change. ${ }^{[1]}$ Skin grafts need to be immobilised for five to ten days requiring strict personal hygiene and dietary care whereas rhomboid local flaps do not need so many dressing changes. ${ }^{[12,13]}$

We used rhomboid local flap procedure to reconstruct defects caused by firearm injuries, which has been traditionally used for reconstructing defect after breast cancer surgeries, burn contractures and similar defects.

Our short case series indicates that rhomboid local flaps can be safely used to reconstruct moderate size skin defects due to firearm injuries. 


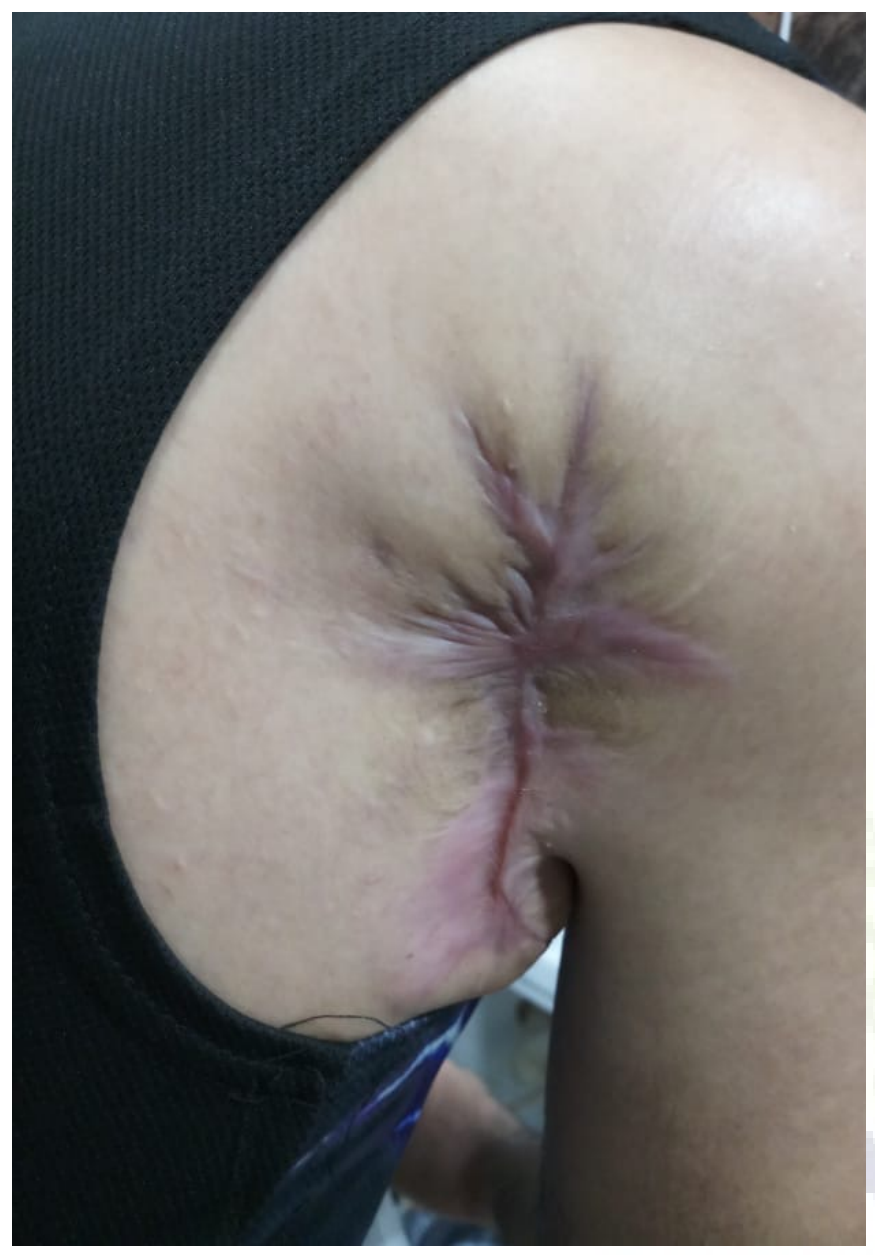

Figure 11: Post wound healing contracture.

\section{Conclusion}

Limberg local flap is a very versatile and robust flap, easy to learn and can be tailored to suit the wound defect in firearm injuries. Since, this is a geometrical flap, there is no dog-ear while rotating the flap. It provides a good padded skin cover of the area of firearm wound.

\section{Acknowledgement}

A sincere thanks goes to our humble colleague and teacher, Dr Lewis for his continued encouragement and wisdom. We also thank Dr Ajay Simon Richard for his dynamism and lovable attitude, ever ready to help with keen interest.

\section{References}

1. Agarwal BB. Surgeon Society of Jaipur, ASI Rajasthan Chapter. 2015;

2. Chasmar LR. The versatile rhomboid (Limberg) flap. Canadian Journal of Plastic Surgery. 2007;15(2):67-71. Available from: https://dx.doi.org/10.1177/229255030701500207. doi:10.1177/229255030701500207.

3. Aydin OE, Tan O, Algan S, Kuduban SD, Cinal H, Barin EZ. Versatile Use of Rhomboid Flaps for Closure of Skin Defects. The Eurasian Journal of Medicine. 2011;43(1):18. Available from: https://dx.doi.org/10.5152/eajm.2011.01. doi:10.5152/eajm.2011.01.

4. Thomson $\mathrm{CH}$, Choudry $\mathrm{M}$, White $\mathrm{C}$, Mecci M, Siddiqui H. Multi-disciplinary management of complex pressure sore reconstruction: 5-year review of experience in a spinal injuries centre. The Annals of The Royal College of Surgeons of England. 2017;99(2):169-174. Available from: https://dx.doi.org/ 10.1308/rcsann.2016.0227. doi:10.1308/rcsann.2016.0227.

5. Koshima I, Moriguchi T, Soeda S, Kawata S, Ohta S, Ikeda A. The Gluteal Perforator-based Flap for Repair of Sacral Pressure Sores. Ovid Technologies (Wolters Kluwer Health); 1993. Available from: https://dx.doi.org/10.1097/00006534199304000-00017. doi:10.1097/00006534-199304000-00017.

6. Thorne CH, Beasley RW, Barlett SP, Aston SJ, Gurtner GC, Spear SL;. Available from: https://www.goodreads.com/book/ show/21729.Grabb_and_Smith_s_Plastic_Surgery.

7. Fee WE, Gunter JP, Carder HM. RHOMBOID FLAP PRINCIPLES AND COMMON VARIATIONS. The Laryngoscope. 1976;86(11):1706-1711. Available from: https://dx.doi.org/10.1288/00005537-197611000-00013. doi:10.1288/00005537-197611000-00013.

8. Jayarajan R. Reconstructive Options for Cutaneous Defects of the Nose: A Review. EMJ Dermatol. 2016;4(1):102-110.

9. Paul S;. Available from: https://link.springer.com/chapter/10. 1007/978-3-319-20937-1_6.

10. Webster RC, Davidson TM, Smith RC. The Thirty Degree Transposition Flap. The Laryngoscope. 1978;88(1):85-94. Available from: https://dx.doi.org/10.1002/lary.1978.88.1.85. doi:10.1002/lary.1978.88.1.85.

11. Khan PS, Hayat H, Hayat G. Limberg Flap Versus Primary Closure in the Treatment of Primary Sacrococcygeal Pilonidal Disease; A Randomized Clinical Trial. Indian Journal of Surgery. 2013;75(3):192-194. Available from: https:// dx.doi.org/10.1007/s12262-012-0430-y. doi:10.1007/s12262012-0430-y.

12. Gumus N. A New Approach to the Antecubital Scar Contracture: Rhomboid Rotation Flap. J Plast Reconstr Aesthet Surg. 2010;63(8):1392-1395.

13. Gwynn BR, Williams CR. Use of the Limberg Flap to Close Breast Wounds After Partial Mastectomy. Ann R Coll Surg Engl. 1985;67(4):245-251. 
Copyright: (C) the author(s), 2020. It is an open-access article distributed under the terms of the Creative Commons Attribution License (CC BY 4.0), which permits authors to retain ownership of the copyright for their content, and allow anyone to download, reuse, reprint, modify, distribute and/or copy the content as long as the original authors and source are cited.

How to cite this article: Mir SH, Lewis HM, Richard S, Arunmozhidevan H. Versatility of Limberg and Its Modified Flaps in Post Firearm Wounds - A Case Series. Asian J. Med. Res. 2020;9(3):4-10.

DOI: dx.doi.org/10.47009/ajmr.2020.9.3.SG2

Source of Support: Nil, Conflict of Interest: None declared. 